\title{
GAMBARAN INSTALASI PENGOLAHAN AIR LIMBAH DI PT. SO GOOD FOOD PESAWARAN LAMPUNG
}

\author{
Abiyyu Jaya Sakti ${ }^{1)}$
}

\begin{abstract}
Abstrak
PT. So Good Foof adalah perusahaan yang memproduksi sosis, kornet, nugget, dan bakso. Limbah cair yang dihasilkan bersumber dari bagian pemotongan ayam dan ruang produksi sosis, dengan volume sekitar $260 \mathrm{~m}^{3} /$ hari. Penelitian bertujuan mengetahui gambaran pengolahan limbah cair di PT. So Good Food Pesawaran Lampung, meliputi sumber air limbah, debit air limbah, kontruksi yang di gunakan, proses pengolahan, dan kualitas air limbah.

Penelitian ini bersifat deskriptif, untuk memberikan gambaran sistem pengolahan limbah cair, mulai dari sumber air limbah, kualitas sebelum diolah, debit, konstruksi, proses, dan pemeriksaan kualitas setelah pengolahan. Penelitian ini dilaksanakan pada Mei 2018. Pengumpulan data melalui pengukuran langsung, observasi dan wawancara terhadap pengelola IPAL. Kualitas diukur pada parameter $\mathrm{BOD}_{5}, \mathrm{COD}$, TSS, $\mathrm{pH}$, Amoniak bebas, dan Minyak Lemak, selanjutnya dibandingkan dengan Peraturan Mentri Lingkungan Hidup No. 5 Tahun 2014 tentang Baku Mutu Air Limbah.

Hasil penelitian mendapatkan bahwa PT. So Good Food Pesawaran Lampung memiliki 2 tempat penghasil limbah cair yaitu Rumah Potong Ayam (RPA) dan Ruang produksi sosis, dengan debit ratarata perhari $489 \mathrm{~m}^{3} /$ hari. Kontruksi IPAL menggunakan bata semen, dan pengolahan menggunakan proses biologi. IPAL mampu memperbaiki kualitas limbah cair pada parameter $\mathrm{pH}, \mathrm{COD}, \mathrm{BOD}$. Namun pada beberapa parameter masih melebihi baku mutu yang diperbolehkan, yaitu TSS, Amoniak bebas, minyak dan lemak. Perlu dilakukan perbaikan sistem pengolahan limbah cair agar seluruh parameter tidak melebihi baku mutu yang ditentukan.
\end{abstract}

Kata Kunci : Limbah cair, IPAL, BOD, COD

1) Alumni Jurusan Kesehatan Lingkungan Poltekkes Kemenkes Tanjungkarang

\section{PENDAHULUAN}

Industri adalah suatu usaha, proses atau kegiatan pengolahan bahan baku baik bahan mentah ataupun bahan setengah jadi agar menjadi barang yang bernilai ekonomis lebih tinggi dan bermanfaat bagi masyarakat. Dalam Kamus Besar Bahasa Indonesia (KBBI) Industri di definisikan sebagai perusahaan untuk membuat, memproduksi atau menghasilkan barang-barang.

Pertumbuhan industri khususnya di Indonesia semakin meningkat dan berkembang, mengikuti kubutuhan dan ekonomi. Pertumbuhan industri harus diikuti dengan perlindungan terhadap lingkungan, terutama pengolahan limbah yang dihasilkan. Menurut Karmana (2007), pengelolaan dan pengolahan limbah bertujuan agar manusia dan lingkungan tetap terjaga dari dampak yang di timbulkan dari hasil kegiatan industri. Kegiatan manusia yang menghasilkan limbah, antara lain kegiatan industri, transportasi, rumah tangga dan kegiatan lainnya.

Limbah cair merupakan sisa buangan hasil suatu proses yang sudah tidak dipergunakan lagi, baik berupa sisa industri, rumah tangga, peternakan, pertanian, dan sebagainya. Komponen utama limbah cair adalah air (99\%) sedangkan komponen lainnya bahan padat yang bergantung asal buangan tersebut (Rustama et. Al, 1998; Matahelumual, 2007).

Industri dan kegiatan lainnya yang mempunyai air buangan yang membentuk limbah cair dalam skala besar harus melakukan penanganan agar tidak berdampak pada lingkungan, karena jumlah polutan di dalam air menjadi semakin tinggi. Pada dasarnya ada dua alternative penanganan yaitu membawa limbah cair ke pusat pengolahan limbah, atau melakukan pengolahan sendiri dengan membangun IPAL yang terdiri dari tiga tahap proses, yaitu pengolahan primer, sekunder, dan tersier (Sunu, 2001). 
Setiap Industri diharuskan mengelola limbah yang dihasilkannya sehingga memenuhi persyaratan standar baku mutu limbah cair, sesuai dengan Peraturan Mentri Lingkungan Hidup Republik Indonesia No. 5 Tahun 2014 Tentang Baku Mutu Air Limbah. PT. So Good Food didirikan pada tahun 1995 dengan nama PT. Supra Sumber Citra, berganti nama menjadi PT. So Good Food Lampung pada bulan april 2010. PT So Good Food Pesawaran Lampung beralamatkan di Jalan Raya Negeri Sakti KM 12 Desa Negeri Sakti, Kecamatan Gedong Tataan, Kabupaten Pesawaran Provinsi Lampung. Produk yang dihasilkan adalah sosis, kornet, nugget, dan bakso, dengan distribusi ke seluruh Provinsi dan Kabupaten di Indonesia.

Berdasarkan survei awal yang dilakukan, pengolahan limbah cair menggunakan sistem aerobik, terdiri dari enam bak yaitu, bak sedimentasi I, bak aerasi, bak sedimentasi II, bak filtrasi, bak fakultatif, dan kontrol outlet. Sumber limbah cair $\left( \pm 260 \mathrm{~m}^{3} /\right.$ hari $)$ dari bagian pemotongan ayam dan ruang produksi sosis. Limbah cair yang telah melalui tahap pengolahan dialirkan ke badan air. Pemeriksaan kualitas limbah dilakukan setiap bulan. Penelitian bertujuan mengetahui gambaran instalasi pengolahan limbah cair di PT. So Good Food Pesawaran Lampung.

\section{METODE}

Penelitian ini bersifat deskriptif, yaitu memberikan gambaran sistem pengolahan limbah cair pada setiap tahap pengolahan. Penelitian dilakukan di PT. So Good Food Pesawaran Lampung, pada bulan Mei 2018. Variabel yang dinilai adalah meliputi sumber air limbah, debit air limbah, kontruksi yang di gunakan, proses pengolahan, dan kualitas air limbah.

Data primer diperoleh dengan observasi, wawancara, dan pengukuran. Wawancara dan observasi untuk mendapatkan informasi tentang sumber limbah, desain kontruksi IPAL, dan proses IPAL. Pengukuran untuk mengetahui debit limbah cair dan dimensi dari bangunan IPAL. Pemeriksaan kualitas limbah dilakukan pada kualitas sebelum dan sesudah diolah, dengan parameter $\mathrm{BOD}_{5}, \mathrm{COD}, \mathrm{TSS}, \mathrm{pH}$, Amoniak bebas, dan Minyak Lemak. Pemeriksaan kualitas sampel limbah cair dilakukan di laboratorium Politeknik Kesehatan Tanjungkarang. Hasil pemeriksaan kualitas limbah cair dibandingkan dengan Peraturan
Mentri Lingkungan Hidup No. 5 tahun 2014, tentang Baku Mutu Air Limbah. Sampel.

\section{HASIL}

PT. So Good Food Manufacturing Indonesia pada awalnya bernama PT. Japfa OSI Food Industries yang merupakan join venture antara OSI (Otto and Sons Incorporation) Amerika dan PT. Japfa Comfeed Indonesia yang didirikan pada tanggal 25 Juni 1997. PT. So Good Food Manufacturing bergerak dalam industri pemotongan ayam, pengolahan karkas ayam, dan menghasilkan produk daging olahan. Perusahaan ini berada dibawah naungan Japfa Group,merupakan perusahaan yang bergerak di bidang agroindustri seperti pembibitan dan penetasan ayam, pakan ternak dan vaksin, tambak udang, pengolahan daging, dan sebagainya.

Pada awalnya, perusahaan didirikan untuk memenuhi kebutuhan daging olahan untuk rumah makan cepat saji sebagai Exclusive Supplier. Namun, setelah tidak lagi menjadi Exclusive Supplier, maka perusahaan memperluas usahanya dengan memproduksi sosis, kornet, nugget, dan bakso. Keseluruhan produk telah mendapatkan sertifikat halal dari Majelis Ulama Indonesia (MUI), dan dipasarkan ke seluruh Indonesia.

Sesuai dengan Izin Usaha Industri (nomor 301/1/IU/I/PMA/Pertanian/Industri/Perdaganga $\mathrm{n} / 2012$ ), kapasitas produksi sebesar 5.040.000 ekor ayam/tahun, daging ayam segar 2.160 .000 ekor/tahun, sosis 5000 ton/tahun. Bahan baku utama perusahaan ini adalah daging ayam dengan Nomor Kontrol Veteriner Unit Usaha Pengolah Daging TPD-18110517, dan telah memenuhi syarat keamanan pangan dan halal. Limbah yang dihasilkan terdiri dari limbah organik dan anorganik. Untuk limbah organik dilakukan penanganan limbah sesuai karakteristik limbahnya, sedangkan untuk limbah anorganik dijual sebagai produk.

Sumber limbah cair yang dihasilkan PT. So Good Food Pesawaran berasal dari RPA (Rumah Potong Ayam) dan rumah produksi sosis. Seluruh limbah kegiatan produksi di proses pada Instalasi Pengolahan Air Limbah (IPAL). Debit limbah cair diukur setiap sore hari sebagai debit harian. Rata-rata debit air limbah adalah $489 \mathrm{~m}^{3} /$ hari.

Kontruksi IPAL terdiri dari enam bak, berbentuk persegi, dengan kontruksi bak terbuat dari pasangan bata semen. Bangunan pengolahan terdiri dari Bak Sedimentasi I, Bak 
Aerasi, Bak Sedimentasi II, Bak Filtrasi, Bak Fakultatif dan Bak Outlet. Saluran air limbah menggunakan sistem tertutup dan kedap air, sehingga limbah cair yang diolah pada IPAL tidak bercampur dengan air hujan. Pengaliran limbah menuju IPAL dengan sistem gravitasi melalui perpipaan tertutup. Limbah dari RPA menuju bak Sedimentasi I dengan cara down flow, lalu di alirkan menuju bak aerasi dan bercampur dengan limbah dari produksi sosis di inlet bak aerasi. Dari bak aerasi pertama, dialirkan menuju bak aerasi ke dua dengan cara up flow, selanjutnya dialirkan ke bak sedimentasi II secara down flow. Dari bak Sedimentasi II, air limbah dialirkan ke bak filtrasi secara down flow, lalu air limbah di alirkan ke bak fakultatif dengan pengaliran over flow, selanjutnya dialirkan menuju outlet. Pengolahan limbah cair terdiri dari enam tahap, yaitu :

1. Tahap I (Bak kontrol), berbentuk persegi, berukuran panjang $170 \mathrm{~cm}$, lebar $100 \mathrm{~cm}$, tinggi $90 \mathrm{~cm}$, terbuat dari pasangan bata yang kuat. Air limbah yang masuk ke dalam bak kontrol menuju bak sedimentasi I adalah dari RPA, sedangkan yang masuk ke bak kontrol yang menuju bak sedimentasi II adalah dari bak aerasi. Fungsi bak kontrol adalah sebagai tempat untuk menampung sementara air limbah dan menyaring sampah yang ikut terbawa air limbah.

2. Tahap II (Bak Sedimentasi I), berbentuk persegi panjang dengan 8 bak di dalam nya, dengan ukuran panjang $1.162 \mathrm{~cm}$, lebar 600 $\mathrm{cm}$, dan tinggi $150 \mathrm{~cm}$. bak ini terbuat dari pasangan bata yang kuat berukuran. Pada bak Sedimentasi I ini berfungsi mengendapkan zat padat dan lumpur dalam air limbah yang di lakukan dengan cara gravitasi. Sehingga padatan yang terkandung dalam air limbah akan mengendap pada bak ini.

3. Tahap III (Bak Aerasi), berbentuk persegi panjang dengan ukuran panjang $1.750 \mathrm{~m}$, lebar $1000 \mathrm{~cm}$, dan tinggi $200 \mathrm{~cm}$. Bak ini terbuat dari pasangan bata yang kuat dan terdapat kincir air di tengahnya untuk proses atau usaha untuk menambahkan konsentrasi oksigen yang terkandung di dalam air limbah, sehingga proses oksidasi biologi dari mikroba tersebut bisa berjalan dengan baik.

4. Tahap IV (Bak Sedimentasi II), berbentuk persegi panjang berukuran panjang $1000 \mathrm{~cm}$, lebar $550 \mathrm{~cm}$, tinggi $200 \mathrm{~cm}$. Terbuat dari pasangan bata yang kuat. Pada bak Sedimentasi II ini berffungsi mengendapkan zat padat dan lumpur dalam air limbah yang ada dikarenakan air limbah dari produksi sosis tidak melewati bak sedimentasi I dan di lakukan dengan cara gravitasi. Sehingga padatan yang terkandung dalam air limbah akan mengendap pada bak ini.

5. Tahap VI (Bak Filtrasi), berbentuk persegi berukuran panjang $1000 \mathrm{~cm}$, lebar $500 \mathrm{~cm}$, tinggi $150 \mathrm{~cm}$. Terbuat dari kolam alam. Gambar terlampir. Bak filtrasi berfungsi untuk proses pemisahan zat padat dari fluida (cair maupun gas) yang membawanya menggunakan suatu medium berpori atau bahan berpori lain untuk menghilangkan sebanyak mungkin zat padat halus yang tersuspensi dan koloid. Selain dapat mereduksi kandungan zat padat, filtrasi dapat pula mereduksi kandungan bakteri, menghilangkan zat warna, rasa, bau, besi dan mangan.

6. Tahap VI (Bak Fakultatif), berbentuk persegi panjang, berukuran panjang 1000 $\mathrm{cm}$, lebar $500 \mathrm{~cm}$, tinggi $150 \mathrm{~cm}$. Terbuat dari kolam alam, gambar terlampir. Berdasarkan fungsinya kolam fakultatif berfungsi mendegradasi air limbah yang bebannya tidak terlalu tinggi $(100-400 \mathrm{~kg}$ $\mathrm{BOD} / \mathrm{Ha}$ /hari pada suhu udara $20-25^{\circ} \mathrm{C}$ ), hal ini dilakukan agar jumlah populasi alga dalam perairan tetap terjaga, mengingat oksigen terbesar kolam yang sangat di perlukan bakteri anaerob untuk mendegradasi bahan anaerob berasal dari algae. Karena keberadaan algae inilah kolam bewarna hijau. Selain mendegradasi bahan anaerob, pada kolam fakultatif juga terjadi degradasi berbagai jenis mikroorganisme penyebab penyakit. Bak Ini juga difungsikan sebagai kolam biologi sebelum di buang ke badan air.

PT. So Good Food Pesawaran memeriksakan kualitas air limbahnya setiap 1 bulan sekali di UPTD laboratoriun Dinas Lingkungan Hidup untuk mengkontrol kualitas limbah cair sebelum dan sesudah dilakukan pengolahan. Dalam penelitian ini sampel air limbah di PT. So Good Food pesawaran pengambilan sampel pada inlet dan outlet pada IPAL, selanjutnya sampel di periksa di laboratorium terpadu Poltekkes Kemenkes Tanjung Karang. 
Hasil pemeriksaan kualitas limbah cair mendapatkan parameter $\mathrm{pH}, \mathrm{COD}, \mathrm{BOD}$ telah sesuai dengan baku mutu limbah cair. Namun pada beberapa parameter masih melebihi baku mutu yang diperbolehkan, yaitu TSS, Amoniak bebas, minyak dan lemak.

\section{PEMBaHASAN}

Rumah Potong Ayam melakukan kegiatan pemotongan ayam dan pembersihan bulu, sehingga limbah cair berupa air limbah pencucian bulu, cucian darah, dan serpihan kulit dan daging ayam. Pada ruang produksi pengolahan daging, limbah cair yang dihasilkan berupa air sisa pemasakan dan pencucian daging. Berdasarkan hasil pengukuran dan perhitungan, debit air limbah yang di hasilkan dari kedua sumber limbah cair sebanyak 489 $\mathrm{m}^{3} /$ hari. Diagram alir sumber limbah cair disajikan pada Gambar 1.

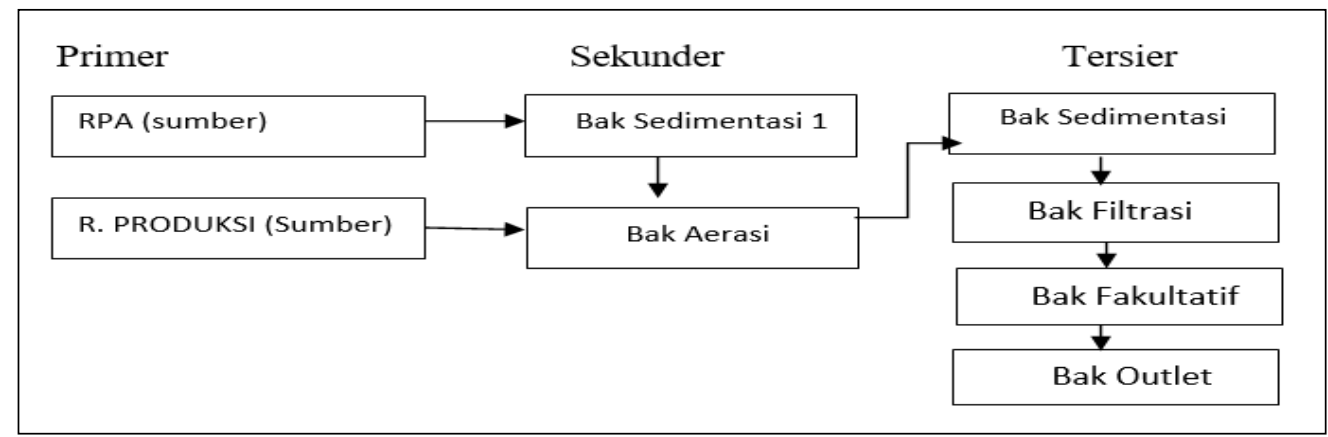

Gambar 1. Diagram alir sumber limbah cair

Menurut Asmadi (2013), bahan bangunan IPAL sebaiknya terbuat dari beton cor atau fiber glass. Dari hasil penelitian diketahui bahwa konstruksi IPAL di PT. So Good Food Pesawaran sudah terbuat dari beton cor dan pasangan bata, namun pada bak filtrasi dan fakultatif masih terbuat dari lubang galian. Saluran air limbah sudah menggunakan sistem tertutup, dilengkapi dengan alat ukur debit.

Hasil observasi juga mendapatkan bahwa kincir air (aerator) yang terdapat pada bak Aerasi hanya bergerak pada siang hari, sehingga proses pengolahan limbah tidak berjalan efektif pada malam hari. Seharusnya kincir sebagai penyuplai udara untuk proses aerasi bekerja selama 24 jam agar proses penguraian biologis dapat bekerja secara optimal. Sehingga, sistem IPAL di PT. So Good Food belum melakukan tahapan pengolahan limbah cair secara baik. Menurut Sugiharto (1987), pengolahan air limbah dapat dikelompokan menjadi beberapa tahap yaitu: a) Pengolahan pendahuluan (pre treatment), terdiri dari saringan (bar screen), pencacah (comminutor), bak penangkap pasir (grit chamber), penangkap minyak dan lemak (skimer and grease trap), dan bak penyetaraan (equalization basin); b) Pengolahan pertama (primary treatment), terdiri dari bak pengumpul, dan bak sedimentasi; c) Pengolahan kedua (secondary treatment), terdiri dari Bak biofilter anaerob-aerob, Bak aerasi, Unit lumpur aktif, Pengolahan ketiga (tertiaty treatment), Pembunuhan bakteri (desinfektion), Pengolahan lanjutan (ultimate disposal).

Hasil pemeriksaan kualitas limbah mendapatkan parameter $\mathrm{pH}, \mathrm{COD}$, BOD telah sesuai dengan baku mutu limbah cair. Namun pada beberapa parameter masih melebihi baku mutu yang diperbolehkan, yaitu TSS, Amoniak bebas, minyak dan lemak. TSS (Total suspended solids) merupakan padatan tersuspensi yang dapat menghalangi masuknya sinar matahari ke dalam air sehingga mengganggu proses fotosintesis dan menyebabkan turunnya oksigen terlarut dalam air. Hasil pemeriksaan TSS bagian inlet pada pagi hari sebesar $276 \mathrm{mg} / \mathrm{L}$, dan sore hari sebesar $203 \mathrm{mg} / \mathrm{L}$. Sedangkan pada outlet sebesar $120 \mathrm{mg} / \mathrm{L}$ dan $114 \mathrm{mg} / \mathrm{L}$. Hasil ini menunjukan penurunan nilai TSS, namun masih berada di atas baku mutu. Sehingga perlu dilakukan upaya peningkatan efektifitas IPAL antara lain menggunakan up flow dan down flow pada bak filtrasi, sehingga partikel dapat tersaring dengan baik.

Amonia bebas $\left(\mathrm{NH}_{3}\right)$ adalah senyawa yang terbentuk dari proses oksidasi bahan organik yang mengandung nitrogen dalam air limbah dengan bantuan bakteri. Adanya amoniak dalam effluent air limbah dapat menjadi indikasi adanya pencemaran senyawa organik yang 
mengandung nitrogen dalam buangan air limbah yang berarti terjadi gangguan proses dalam pengolahan air limbah. Hasil pemeriksaan nilai amoniak pada bagian inlet pagi hari sebesar $10 \mathrm{mg} / \mathrm{L}$, dan sore hari sebesar $26,78 \mathrm{mg} / \mathrm{L}$. Sedangkan pada bagian outlet sebesar 12,15 mg/L, dan 13,30 mg/L. Hasil ini menunjukan penurunan nilai amoniak, namun masih berada di atas baku mutu. Upaya untuk menurunkan parameter amoniak antara lain memastikan proses aerasi berjalan baik selama 24 jam, dengan suplai udara yang memenuhi kebutuhan proses penguraian.

Minyak dan Lemak merupakan merupakan bahan organik bersifat tetap dan sukar diuraikan bakteri. Minyak mempunyai berat jenis lebih kecil dari air sehingga akan membentuk lapisan tipis di permukaan air, sehingga dapat mengurangi jumlah oksigen terlarut dalam air. Hasil analisis di bagian inlet IPAL pada pagi hari sebesar $10 \mathrm{mg} / \mathrm{L}$, dan sore hari sebesar $35,80 \mathrm{mg} / \mathrm{L}$. Sedangkan hasil pengukuran pada outlet sebesar $11,10 \mathrm{mg} / \mathrm{L}$, dan $10,90 \mathrm{mg} / \mathrm{L}$. Walaupun menunjukkan penurunan namun masih belum memenuhi baku mutu. Penurunan nilai parameter minyak dan lemak dapat dilakukan dengan penambahan bak penangkap lemak (greas trap) serta melakukan pembersihan lapisan minyak dan lemak pada greas trap secara teratur.

\section{KESIMPULAN}

Berdasarkan hasil penelitian diketahui bahwa pengolahan limbah cair di PT. So Good Food Pesawaran Lampung menggunakan sistem biologis, dengan debit limbah rata-rata sebesar $489 \mathrm{~m}^{3} /$ hari. Pengolahan limbah cair dilakukan dalam enam bak pengolahan, yaitu bak kontrol, bak sedimentasi I, bak aerasi, bak sedimentasi II, bak filtrasi, dan bak fakultatif. Hasil pengukuran kualitas limbah mendapatkan parameter $\mathrm{pH}, \mathrm{COD}$, BOD telah sesuai dengan baku mutu limbah cair. Namun pada beberapa parameter masih melebihi baku mutu yang diperbolehkan, yaitu TSS, Amoniak bebas, minyak dan lemak. Perlu upaya peningkatan efektifitas pengolahan limbah dengan merubah sistem aliran pada bak filtrasi menjadi up flow dan down flow, perbaikan sistem penyuplai udara (aerator) pada bak aerasi dan meningkatkan waktu aerasi menjadi 24 jam, menambah jumlah bak penangkap minyak lemak (greas trap), serta melakukan pembersihan greas trap secara teratur.

\section{DAFTAR PUSTAKA}

Asmadi, 2013. Pengelolaan Limbah Medis Rumah Sakit.Gosyeng publising.Yogyakarta.

Departemen Lingkungan hidup dan Kehutanan RI. 2014. Peraturan Mentri Lingkungan Hidup Nomor: 5 Tentang Baku Mutu Air Limbah. Jakarta

Karmana. 2007. 6 Pengertian Limbah Menurut Para Ahli Lengkap [online]. Tersedia http://www.indonesiastudents.com [27 Febuari 2018]

Matahelumual, Bethy Carolina, 2007. Penentuan status mutu air dengan sistem STORET di Kecamatan Bantar Gebang. Jurnal Geologi Indonesia, Vol. 2 No. 2 Juni 2007: 113-118

Rustama, M.M., R. Safitri, I. Indrawati. 1998. Pemanfaatan Limbah Cair Pabrik Tahu Sebagai Media Pertumbuhan Phytoplankton. Laporan Penelitian Fakultas Matematika dan Ilmu Pengetahuan Alam. Universitas Padjajaran. Bandung.

Sugiharto.1987. Dasar-Dasar Pengolahan Air Limbah. Jakarta: Universitas

Indonesia. 190 halaman

Sunu, P., 2001. Melindungi Lingkungan Dengan Menerapkan ISO 1400. Jakarta: PT. Gramedia Widia Sarana Indonesia. 